\title{
Understanding risk perception from floods: a case study from China
}

\author{
$\mathrm{Yi} \mathrm{Ge}^{1} \cdot$ Guangfei Yang ${ }^{1} \cdot$ Xiaotao Wang ${ }^{1} \cdot$ Wen Dou$^{2} \cdot$ Xueer Lu ${ }^{1} \cdot$ Jie Mao ${ }^{1}$
}

Received: 5 February 2020 / Accepted: 29 June 2020 / Published online: 5 January 2021

(C) The Author(s), under exclusive licence to Springer Nature B.V. part of Springer Nature 2021

\begin{abstract}
Understanding and improving the public risk perception have become an important element in the management of flood risk. In China, the risk government is of so-called nationwide catastrophe response mode which is different from the widely adopted "bottom up" risk governance mode in the Western countries. Such a particular mode may make Chinese people perceive risk in a different way from people in other countries. Hence, a further discussion of risk perception is of great value in China. This paper presents a case study on the public perception of flood hazard and flood risk in a city prone to floods. The relationship between risk perception and exposure was examined by spatial analysis. Meanwhile, inferential testing with chi-squared tests was undertaken regarding experience, social trust, and protective behaviors. Our results suggest that (1) the relationship between exposure and risk perception of people in Nanjing is positive and statistically significant, (2) flood experience was strongly related to risk perception, (3) trust showed a significant relationship to risk perception, and (4) people who have perceived the probability of floods and associated loss of life have a higher willingness to take more protective measures. These findings will help local government to develop effective flood risk communication strategies for improving public awareness creation, emergency response and preparedness.
\end{abstract}

Keywords Risk perception - Experience $\cdot$ Social trust $\cdot$ Protective behaviors $\cdot$ Chi-squared test

Wen Dou

douw@seu.edu.cn

Yi Ge

geyi@njnu.edu.cn

Guangfei Yang

ygf218@126.com

Xiaotao Wang

chipie@njnu.edu.cn

Xueer Lu

cherluk@163.com

Jie Mao

mj15651768202@163.com

1 School of the Sociology and Development, Nanjing Normal University, Nanjing 210097, China

2 School of Transportation, Southeast University, Nanjing 210018, China 


\section{Introduction}

According to historical records, China has had a particularly long and terrible history of flooding (Jiang et al. 2005).In recent years, as a result of climate change, floods have become increasingly frequent and have represented about one-third of all natural disasters (Lechowska 2018). Flooding is a major threat to many cities worldwide and will also continue to pose more significant threats to developing countries. In China, floods have caused about $37.2 \%$ of economic losses and about $11.7 \%$ of the death toll of all meteorological disasters (Xie et al. 2018). As an example, the severe flooding which struck the Yangtze River region in 1998 has affected 223 million people, led to 3704 deaths and 44 billion USD in damage (Qin et al. 2015). One year later, a severe flood disaster inundated the Taihu lake basin and resulted in property damage of 16 billion USD (Liang et al. 2011). The 2011 China floods caused by heavy rain were a series of floods which lasted for nearly four months, which struck portions of 12 provinces in China. These affected over 36 million people, killed at least 355 people and caused direct economic losses of nearly 6.5 billion USD (Wikipedia 2012). In 2016, another flood of historic proportions swamped China, the costs of which exceeded a billion USD (NASA 2016). In 2019, heavy rains triggered floods in southern and central China. According to the Ministry of Emergency Management (MEM) of China, over 6 million have been affected, with 388,000 displaced. Besides global warming, several converging factors have made China more vulnerable to floods in the coming decades, such as the highly rapid urbanization characterized by increasing imperviousness and unwieldly urban expansion ( $\mathrm{Su}$ and Duan 2017), growth in high-value development in flood-prone areas (Thistlethwaite et al. 2018).

Future scenarios of high risks from floods should receive more attention; as such, improving the reliability of integrated flood risk management practices has been recognized as a significant part of establishing a resilient society in China (Xie et al. 2018). Risk perception is an important part of disaster risk management and determines whether risk management is successful in reducing vulnerability (Bubeck et al. 2012).

Comparing the Chinese government's efforts against the snow disaster in southern China in 2008, or the Wenchuan Earthquake in 2008, with the Federal government response to Hurricane Katrina, it can be concluded that the risk government in China is of so-called nationwide catastrophe response mode (the top down mode, namely, the powerful government model), which is different from "bottom up" risk governance mode used widely in the Western countries and other Asian countries (Shi et al. 2013). Hence, such a particular mode may make Chinese people perceive risk in a different way from people in other countries. As the mode of disaster response is not necessarily coupled with the government model, it is possible that other countries will take the mode, especially when facing with catastrophes. Therefore, a further discussion of risk perception is of great value. To this end, this paper aims to provide an insight into flood risk perception by dealing with a case study of risk perception conducted in Nanjing - a city within the floodplain of the Yangtze River Delta, China.

The remainder of this paper is organized as follows. The next section reviews scholarly literature about specific elements of risk perception and summarizes their relationship. Then, the study area and research methods are described. The fourth section analyzes the results. In detail, descriptive analyses of risk perception, experience, social trust and protective behaviors is provided firstly. Then, their spatial pattern is visualized with the aid of QGIS 3.4.10. Furthermore, spatial statistics, correlation analysis and inferential testing with chi-squared tests are undertaken regarding risk perception, exposure, experience, 
social trust, and protective behaviors. Finally, the findings are discussed in the concluding section.

\section{Literature review}

Risk perception refers to individual beliefs or subjective judgements about the probability of hazard and the negative consequences of a hazard (Lechowska 2018; Shin et al. 2019). This is an important concept in disaster risk management because it influences which hazards people care about and how they deal with them. Generally, the public usually evaluates risks based on their subjective perceptions and intuition, as well as inferences from a limited set of information, including media coverage, but seldom counted on knowledges of objective risk factors (Shin et al. 2019). In the 1960s, the study of risk perception stemmed from the observation of differing views on risk between the public and experts. These traditional researches on risk perception generally focused on characteristics of specific hazards as determinants of risk perception. At present, researchers recognize that we need to place emphasis on the social, political, and cultural contexts where risk is embed$\mathrm{ded}$, and the associations between people, risk perception, and the places where risk is experienced (Cardwell and Elliott 2019). In 2018, Lechowska distinguished 22 influencing factors generally considered in risk perception and divided them into six groups according to their nature (Lechowska 2018): (1) the cognitive group-worry and direct experience; (2) behavioral group - preparedness, trust in government, and public protection measures; (3) socioeconomic and demographic group - age, gender, incomes, education, household size (children), home ownership, cellar ownership; (4) geographical group-location (hazard), hazard proximity, type of building (living on ground floor); (5) informational groupawareness (knowledge), indirect experience (media); (6) and the contextual group - culture, religion, history, political system, and social bonds. Limited by available funding, this study only focused on four factors: exposure, experience, trust and protective behaviors.

\subsection{Exposure and risk perception}

Exposure can be defined as the nature and degree to which a receptor (e.g., people, infrastructure, or the urban communities, etc.) is exposed to natural hazards (Kaźmierczak and Cavan 2011). Exposure to natural hazards can be evaluated by algorithms or spatial models (Bui et al. 2018; Khosravi et al. 2019; Tien Bui et al. 2019; Y. Wang et al. 2019). As one of the factors of risk of natural disasters, exposure is important for risk perception. However, there is no consistent answers among the researches. On one hand, Krasovskaia et al. found that people in a flood-affected area of Norway perceived a low risk of flooding (Krasovskaia et al. 2001). Similar results were found in other countries, such as Pagneux et al., who presented their case study in an Icelandic town prone to ice-jam floods in Iceland. They also found that local residents have poor risk perception about inundations in the area (Pagneux et al. 2011). Ludy and Kondolf confirmed this opinion with their study in a floodplain of the United States (Ludy and Kondolf 2012). They revealed that the well-educated professionals did not understand the risks associated with the floodplain. With a case study in Vietnam, Hung et al. also found a low public perception of catastrophic flood risk among communities in floodplain areas outside a river dyke in 2007 (Hung et al. 2007). On the other hand, some authors suggested that exposure is related to risk perception. Ruin et al. used cognitive mapping combined with GIS data processing to assess motorists' flash-flood 
risk perception, and found that risk perception was high when impacts were observed close to the place of residence (Ruin et al. 2007). Heitz et al. did a study of local stakeholders' perceptions of muddy flood risk in three high-risk catchments of France; their results highlight significant differences in respondents' perceptions, which particularly depended on their location (Heitz et al. 2009). Recently, researchers are interested in the relationship between risk perception and hazard proximity. Hazard proximity is among the examples of exposure Thistlethwaite et al. have suggested (Thistlethwaite et al. 2018). Hazard proximity is defined by the geographic distance from the hazard source, such as nuclear power facilities, chemical plants, flooding riverbeds, volcanoes and earthquakes (Arias et al. 2017; Lindell and Hwang 2008b; Zhanget al. 2010). Still, there are conflicting research findings regarding the correlations of hazard proximity and risk perception. Some researchers have found a negative correlation. For example, Arias et al. revealed that hazard proximity relation on the risk perception for earthquake/tsunamis for inhabitants of the coastline remains negative and statistically significant (Arias et al. 2017). The study of risk perception made by Siegrist and Gutscher in Switzerland and the study of perception to flood risk made by Brilly and Polic also supported Arias's findings (Brilly and Polic 2005; Michael Siegrist and Gutscher 2006). In the meanwhile, some other studies did not supported such conclusion (Arias et al. 2017). In addition, Lindell and Hwang indicated that the effect of hazard proximity on risk perception might be affected by increased hazard knowledge receipt from media and authorities or observable environmental cues (Lindell and Hwang 2008b).

\subsection{Experience and risk perception}

Experience includes two dimensions: direct experience (e.g., experiencing a natural disaster with one's own eyes) and indirect experience (e.g., witnessing friends or family experience natural disasters or learning from media and education). Several researches have shown that direct experience positively relates to risk perception, such as Miceli's study in an Alpine Valley in Italy, Ruin's finding about individuals' flood experience, Ming-Chou's research about victims in landslides, and Paton's study of the risk perception of volcanic eruptions (Miceli et al. 2008; Ming-Chou et al. 2008; Ruin et al. 2007). However, other researches also documented that disaster experience can decrease individuals' risk perception; for instance, Hall's study about homeowners' reactions in the Oregon coast range, and Scolobig's findings from case studies in an Alpine Region (Hall and Slothower 2009; Scolobig et al. 2012). Wachinger concluded that the severity of individual damage experienced in hazard events shapes the respondents' perceptions. Thus, low-severity and seldom-experienced hazards can produce a false sense of security; only high-severity hazards can heighten risk perception. Indirect experience includes education, media, and hazard witnesses (Wachinger et al. 2013). Siegrist indicated that, for people with personal experience of hazards, media coverage affected risk perception weakly (Michael Siegrist and Gutscher 2006). However, Felgentreff argued that media reports stimulated people in the German Odra river basin to recall their experience of a flood in 1997 (Felgentreff 2003).

\subsection{Trust and risk perception}

In the domain of risk perception, trust is the degree of public reliance on government agencies in managing a risk (Choon et al. 2019). The relationship between trust and risk perception is an important issue that is also very much debated in risk perception research. 
Some studies have found a strong correlation between trust and the perception of hazards. In 1992, Flynn et al. examined the relationship between risk perception and trust with structural modeling, and negative relationship was found in their study (Flynn et al. 1992). Three years later, Biel and Dahlstrand also found a strong negative relationship with a study conducted in four municipalities of Sweden (Biel and Dahlstrand 1995); however, as the result could not be replicated, it is thought as an outlier by Viklund (Viklund 2003). Siegrist demonstrated that trust has negative effects on the perceived risk of gene technology (Siegrist 2000). Bronfman et al. indicate that trust has a high influence on risk perception and the degree of acceptability (Bronfman et al. 2008). Terpstra found that people could feel at less risk of floods if their trust in experts and authorities is high (Terpstra 2011). However, these opinions are challenged by other researchers. Sjöberg tested the effect on risk perception by a general trust measure and a specific trust measure. The data on trust and risk perception point to only a weak relationship between the two in various hazard situations (Sjöberg 2001). Siegrist and Cvetkovich proved that the higher the levels of public's knowledge about a risk, the weaker the relationship between trust and risk perception (M. Siegrist and Cvetkovich 2000). This finding was replicated by Sjöberg ( $\mathrm{Sj}$ “oberg 2002). Viklund investigated the relationship between trust and risk perception in four European countries (Sweden, Spain, UK, and France) with survey data in 1996. He concluded that trust was a significant predicator of perceived risk, but the strength of correlations varied from weak to moderate in different countries. This relationship also varied depending on the type of risk and trust measure (Viklund 2003).

\subsection{Risk perception and protective behaviors}

Thistlethwaite et al. found that the influence of individual risk perception on adapting protective behavior alleviating risk had become the subject of considerable research in recent years (Thistlethwaite et al. 2018). A literature review revealed that predicting disaster preparedness using risk perception has remained tenuous and inconsistent (Bubeck et al. 2012; Lechowska 2018; Thistlethwaite et al. 2018; Yong and Lemyre 2019). Some research has indicated that mitigation behavior is clearly related to risk perception; for instance, Reynaud et al. discovered that some flood-protective behaviors of Vietnamese households are driven by the perception of flood risks (Nguyen 2013). In contrast, other studies showed that no statistically significant relationship had been found between risk perception and disaster preparedness. As an example, Lindell and Perry indicated that risk perception and disaster preparedness are weakly correlated or uncorrelated to each other in their empirical study (Lindell and Perry 2000). Thieken et al. found that risk perception was rarely associated with preparedness in three different flood-affected regions in Germany (Thieken et al. 2007). This result was supported by Scolobig et al., who presented an Italian case study on flood mitigation behavior (Scolobig et al. 2012). Also, Wachinger et al. found that there was a complex relationship between risk perception and preparedness: individuals with a low risk perception may prepare themselves for natural hazards, while the opposite can also occur (Wachinger et al. 2013). Choon et al. explored the association between risk perception and climate change mitigation behaviors, but the proposed influence of risk perception on mitigation behaviors was not supported (Choon et al. Tan 2019). Wachinger et al. call this weak relationship between risk perception and personal actions "the risk perception paradox" and explain it as follows: (1) individuals choose to accept risk because of the benefits perceived exceeding the potential negative impacts, although they understand the risk; (2) individuals do not realize any agency for actions and transfer the responsibility for 
action to others although they understand the risk; and (3) the few resources available limit individuals in changing the situation, although they understand the risk (Wachinger et al. 2013).

Based on the literature review, the relationships between exposure and risk perception, experience and risk perception, trust and risk perception, risk perception and protective behaviors are complicated; even paradoxes or arguments can be found in these researches. Moreover, most of these studies were completed in the regions that under "weak government," such as most of Western countries and Asian countries (e.g., India, Philippines, etc.). However, China adopts the "powerful government model," where the risk perception might be quite different from those regions managed by a weak government. Hence, our research was designed to answer these questions: (1) how do the residents in China perceive their flood risk? (2) how is exposure and experience related to risk perception in China? (3) how does risk perception exert effect on social trust and protective behaviors?

\section{Materials and methods}

\subsection{Study area}

The research was conducted in Nanjing, the capital of Jiangsu province in east China. Today, the Nanjing city is composed of 11 districts. In detail, five districts including Gulou, Xuanwu, Qinhuai, Jianye and Yuhuatai are in urban centers with high population density. Another three districts of Jiangning, Qixia and Pukou are in peri-urban areas where both urban and rural characteristics can be found. And the other three districts of Luhe, Lishui and Gaochun are in rural areas with poor connections to the urban areas (Fig. 1). Nanjing is situated in the Yangtze River Delta, which ranks among the areas with the highest urbanization level, population density, and economic development in China (Ge et al. 2017). The

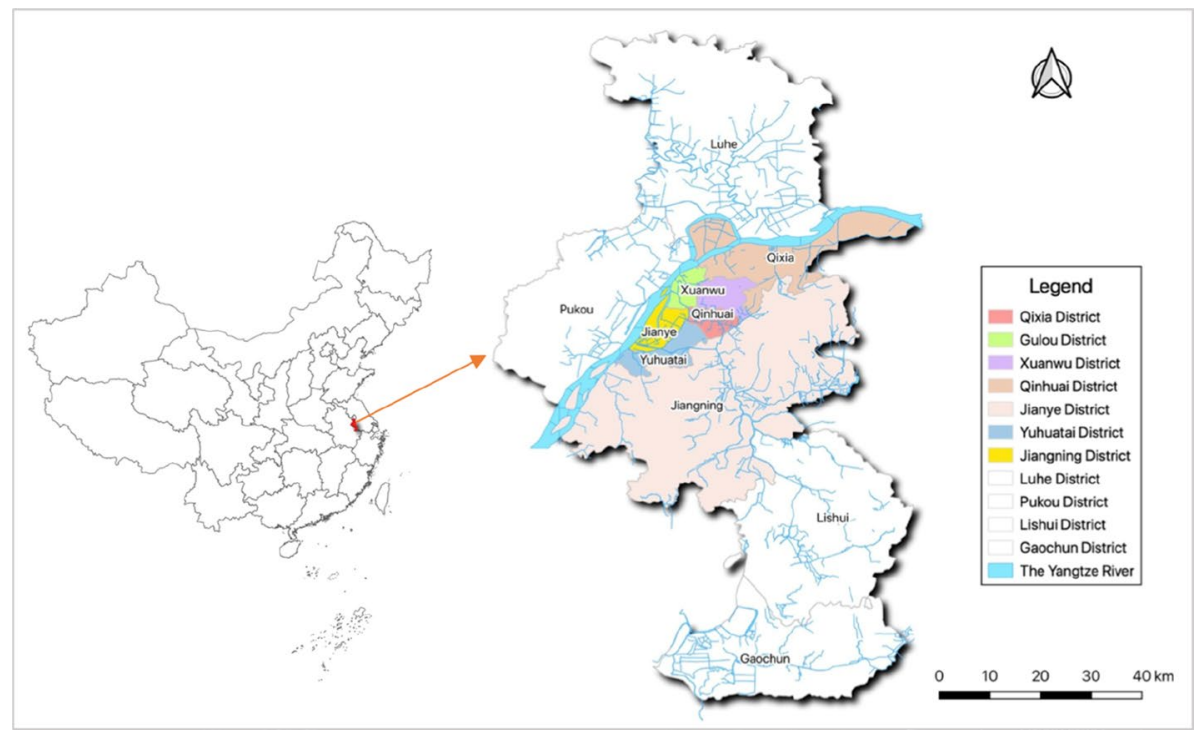

Fig. 1 Study area 
Yangtze River and several of its branches flow through Nanjing, making the city vulnerable to flooding and waterlogging.

\subsection{Sample selection}

A survey was deployed in Spring 2018 and was completed by 702 respondents across the urban areas and peri-urban areas on the southern bank of the Yangtze River. Seven districts, including five urban districts, namely Gulou, Xuanwu, Qinhuai, Jianye, and Yuhuatai, and two peri-urban districts, namely Jiangning and Qixia, are selected as our study area. No respondents were selected in the other four districts: Pukou, Luhe, Lishui and Gaochun. It is because that (1) Pukou locates on the northern bank of the Yangtze River, and (2) Lishui, Luhe and Gaochun are in rural areas. There are 69 communities were selected as illustrated in Fig. 2. These communities cover the most area of impervious surface in the study area of Nanjing. In the heavily flood-hit areas and those in city center, more communities were selected. While, in relatively less affected areas, fewer communities were chosen. In order to recruit our participants, random samples were taken in every community separately. All the questionnaires were distributed via face to face. Investigators who attended to the survey were students having the social survey knowledge and background of natural disaster management. All the respondents in this survey were voluntary and consented, and enough time was given.

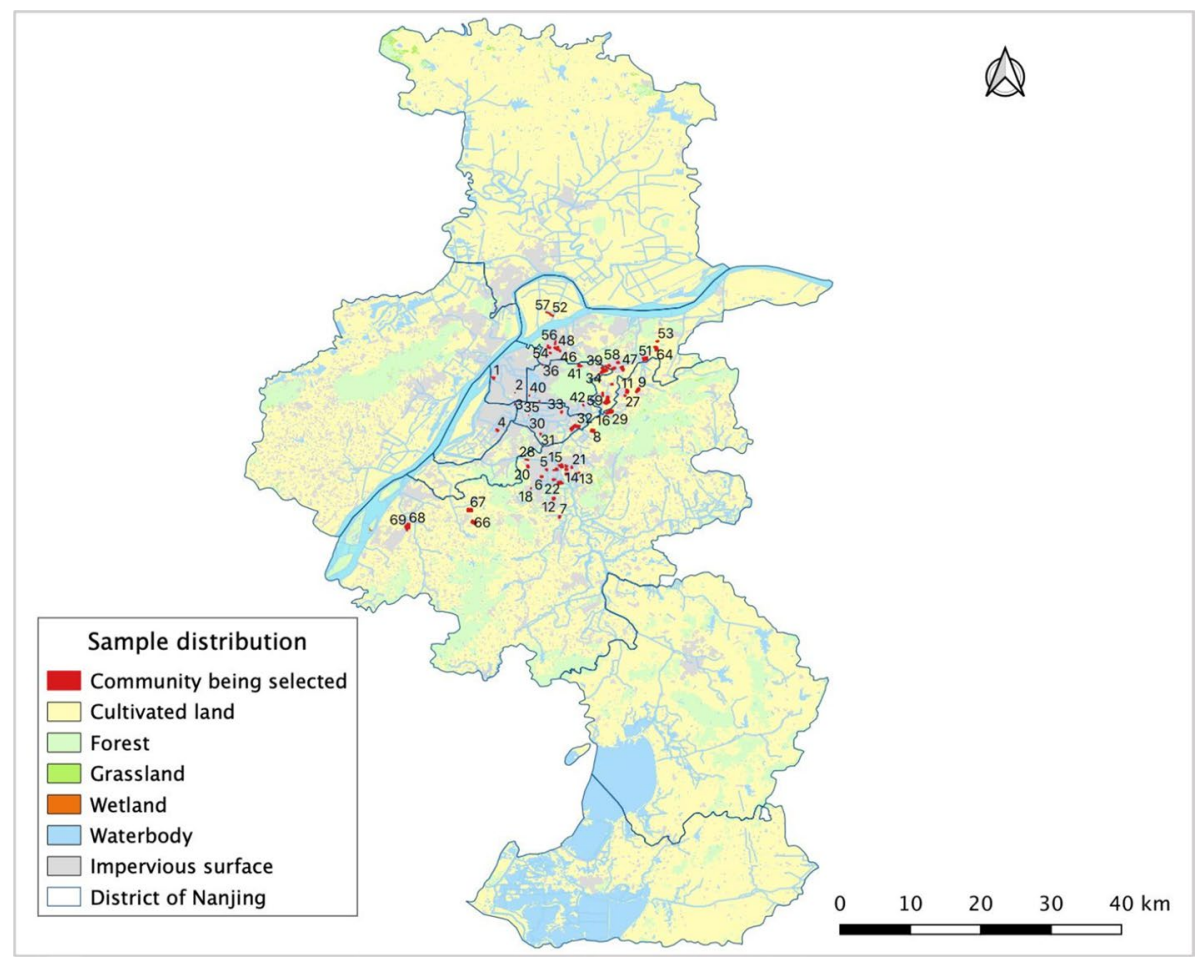

Fig. 2 Communities being selected in study area 


\subsection{Questionnaire design}

To ensure the reliability and validity of the questionnaire, the items were based on existing literature ( $\mathrm{Wu}$ et al. 2018). The structured questionnaire was designed based on five domains: flood perception, experience, flood protection, social trust and demographic data (Table 1).

(1) The domain of flood perception consisted of five questions. The first question compared participants' perceptions about flood with other disasters/problems. As mentioned before, risk perception is the judgment people make about the probability and severity of a hazard; as such, the other four questions were designed regarding probability and severity with a Cronbach's alpha test value of 0.653 . Cronbach's alpha statistic is to provide a measure of the internal consistency of a test or scale (Tavakol and Dennick 2011). Some professionals require a reliability of 0.70 or higher with 0.60 as the lowest acceptable, and 0.8 or greater a very good level. However, values higher than 0.95 are not necessarily good, since they might be an indication of redundancy (Hulin et al. 2001). Hence, the internal consistency of these questions is acceptable. Moreover, a five-point Likert scale denoting the extent of agreement to these four questions (from "1", strongly disagree, to "5", strongly agree) was designed. The reason for using this scale is that a Likert scale is one of the most fundamental and frequently used psychometric tools in educational and social sciences research (Joshi et al. 2015).

(2) The second domain also had five questions related to an individual's disaster experience. The first question examined the participants' direct experience of floods, and

Table 1 The outline of Questionnaire

\begin{tabular}{|c|c|c|}
\hline Domain & ID & Questions \\
\hline \multirow[t]{4}{*}{ Flood perception } & 1 & $\begin{array}{l}\text { What do you think the three most dangerous disasters/problems are in } \\
\text { Nanjing? }\end{array}$ \\
\hline & 2 & Please evaluate the probability of a flood disaster occurring in Nanjing? \\
\hline & 3 & Please evaluate the potential economic losses from floods? \\
\hline & 4 & Please evaluate the potential threats from floods to social stability? \\
\hline \multirow[t]{5}{*}{ Disaster experience } & 1 & Have you ever experienced a flood? \\
\hline & 2 & Have you ever experienced an earthquake? \\
\hline & 3 & Have you ever experienced a landslide? \\
\hline & 4 & Have you ever experienced a typhoon? \\
\hline & 5 & Have you ever experienced a snowstorm? \\
\hline Social trust & 1 & $\begin{array}{l}\text { How much do you trust the following people or institutions during a } \\
\text { flood? }\end{array}$ \\
\hline \multirow[t]{6}{*}{ Flood protection } & 1 & $\begin{array}{l}\text { Do you have the following materials stockpiled in your home for flood } \\
\text { mitigation? }\end{array}$ \\
\hline & 2 & Do you know the location of the nearest hospital to your family? \\
\hline & 3 & Do you know the location of emergency shelters nearby? \\
\hline & 4 & Have you participated in emergency drills or exercise? \\
\hline & 5 & Will you purchase flood insurance if available? \\
\hline & 6 & Are you familiar with flood prevention knowledges? \\
\hline Demographic characteristics & $1-8$ & Gender, age, marital status, ethnicity, education, income, and so on \\
\hline
\end{tabular}


the other four questions were designed to provide a comparison between these experiences and floods. The Cronbach's alpha test value of these five questions was 0.629. Responses to these questions were obtained by a series of check-lists, where " 1 " was regarded as a positive response and " 0 " was regarded as a negative one.

(3) The third domain investigated the social trust of respondents. Nine items were offered on the topic question: family, friend, neighborhood, colleague, volunteer, media organizations, army, government, and NGO. Every item is examined with a 4-point Likert scale denoting the extent of trust (from " 1 ", strongly distrust, to "4", strongly trust). The Cronbach's alpha test value of the questions was 0.895 .

(4) In the domain of "flood protection", six questions were designed to identify participants' protective behaviors. The first question was designed to examine the material stockpiled. Six examples were offered on the topic: food, flashlight, water, medicine, radio, and a first aid kit. Another five questions are about preparedness-related behaviors. Responses to these questions were obtained by a series of check-lists, where a positive response was coded as " 1 " and a negative response was coded as " 0 ". The Cronbach's alpha test value of the questions was 0.792 .

(5) The last domain collected the demographic characteristics of our participants, such as gender, age, marital status, ethnicity, education, and income. Gender, ethnicity, and marital status were dummy variables with one designating male, a member of a minority group, and married, respectively. Age, education, and income were set as categorical variables referring to Wu's study (Wu et al. 2018). Other demographic attributes were examined by two questions as follows: (1) Have you rented or bought the house in which you live? (2) Do you have a family member with a disability? Responses to these were obtained by a check-list, where a positive response was coded as " 1 " and a negative response was coded as "0".

\subsection{Measurement}

Various methods have been used in the research on risk perception. Correlation analysis has been applied in most cases (Kellens et al. 2011; Lechowska 2018; Lindell and Hwang 2008a). Other methods included a Chi squared test (Bradford et al. 2012; Thistlethwaite et al. 2018), independent samples $t$-test (Bradford et al. 2012), one-way analysis of variance (ANOVA) (Avram 2009), regression analysis (Cardwell and Elliott 2019; Cui and Han 2018; She et al. 2019; Wu et al. 2018).

In this paper, results were reported descriptively. Then, each respondent received a score calculated from the mean values of items in each domain separately, named as the risk perception score, experience score, trust score, and preparedness score. All scores were analyzed according to different districts and mapped in QGIS 3.4.10 to display their spatial distribution. The relationship between exposure and risk perception is explored through spatial statistics and Pearson's correlations. In order to examine the relationships between experience and risk perception, trust and risk perception, and behavior and risk perception, inferential testing was done to these variables with chi-squared tests. 


\section{Results}

\subsection{1 Respondents characteristics}

Respondents were somehow evenly distributed across urban and suburban areas in Nanjing, at $45 \%$ and $55 \%$, respectively. The detailed distribution in seven districts was as follows: $13.2 \%$ in Gulou District, $8.8 \%$ in Jianye District, $7.1 \%$ in Qinhuai District, $15.8 \%$ in Xuanwu District, $10.3 \%$ in Jiangning District, 29.5\% in Qixia District and $15.2 \%$ in Yuhuatai District. Among the 702 respondents, 51.6\% were males and $48.4 \%$ were females (Table 2). In total, $44 \%$ were married and $5.4 \%$ were members of minority groups. The majority of respondents $(81.9 \%)$ owned their own residence, while the rest rented. In total, $9.8 \%$ respondents had a family member with a disability. The age of respondents was as follows: $8.8 \%$ were under 18 years of age, $83.2 \%$ between 18 and 60 years of age, and 5.3\% were over 60 years of age. Across Nanjing, $10.56 \%$ of people are under 14 years of age and $10.98 \%$ are over 65 years of age, indicating that our sample covers more adults than the Nanjing average. Income varied in our sample, with 6\% under RMB 60,000, 62.4\% between RMB 60,000 and 120,000, and 31.6\% over RMB 120,000. The annual average income in Nanjing was RMB 98,106 (Chinese Yuan) in 2017, showing that our sample somewhat represents this region. Education varied among the sample, with 3\% being illiterate, $8 \%$ being primary-school-educated, $15.2 \%$ being middle-school-educated, $13.2 \%$ being high-school-educated, and $57.8 \%$ university-educated.

Table 2 Descriptive analysis of socio-demographic characteristics

\begin{tabular}{lcl}
\hline Variables & Frequency $(n)$ & Percentage (\%) \\
\hline Gender (male) & 362 & 51.6 \\
Marital status (married) & 309 & 44 \\
Ethnicity (being a minority) & 38 & 5.4 \\
Being tenants & 127 & 18.1 \\
Having a family member with a & 69 & 9.8 \\
$\quad$ disability & & \\
Age (years) & & \\
$\quad<18$ & 62 & 8.8 \\
18-60 & 584 & 83.2 \\
$>60$ & 37 & 5.3 \\
Income (Chinese Yuan) & & \\
$<60,000$ & 42 & 6.0 \\
$60,000 \sim 120,000$ & 438 & 62.4 \\
$>120,000$ & 222 & 31.6 \\
Education & & \\
Illiterate & 21 & 3.0 \\
Primary & 56 & 8.0 \\
Middle & 107 & 15.2 \\
High & 93 & 13.2 \\
College+ & 406 & 57.8 \\
\hline
\end{tabular}




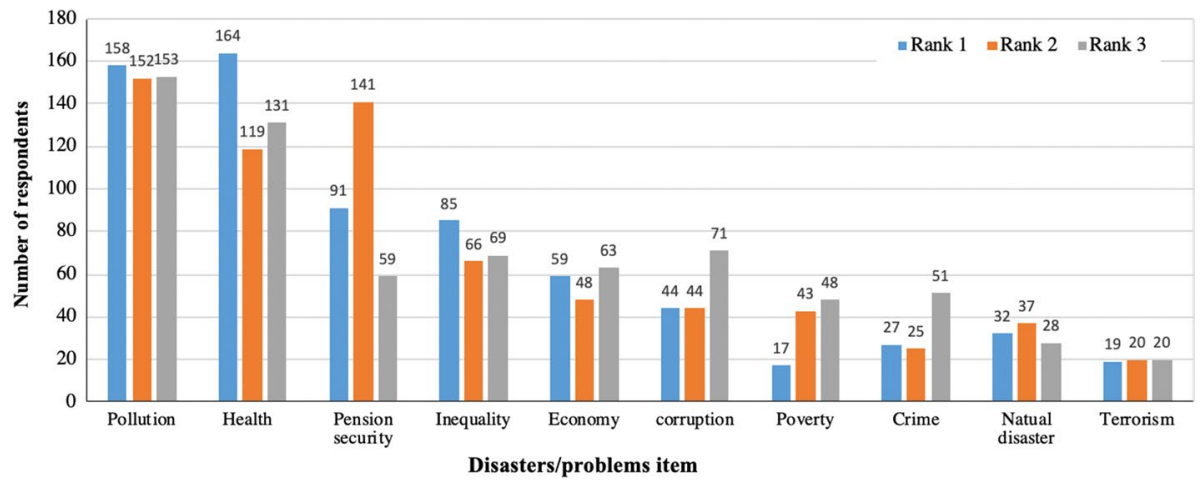

Fig. 3 The top three risks perceived by respondents

Table 3 Descriptive analysis of risk perception

\begin{tabular}{llllll}
\hline Item & Variable & Mean & SD & Min. & Max. \\
\hline 1 & Probability of floods perceived & 3.11 & 1.20 & 1 & 5 \\
2 & Economic losses perceived & 2.36 & 0.99 & 1 & 5 \\
3 & Life losses perceived & 2.27 & 1.05 & 1 & 5 \\
4 & Social stability losses perceived & 2.10 & 0.97 & 1 & 5 \\
\hline
\end{tabular}

\subsection{Outcomes of risk perception, experience, social trust, behavior}

In our survey, the samples were collected in areas prone to floods, whereas the awareness of the risk of natural disaster was found to be fairly low in these areas. Figure 3 is illustrated with the answer to the question "What do you think are the three most dangerous disasters/problems in Nanjing?", In Fig. 3, "Rank 1" counts the respondents who perceives the item as the most dangerous disasters/problem, "Rank 2" and "Rank 3" are defined in the same manner.

According to this Figure, the risk of pollution and health were perceived by the majority of respondents. Only $14 \%$ of our sample thought that natural disasters were among the top three. In addition, social and economic risk was also perceived more than natural disaster risk. This result can be contextualized by understanding that environmental and health incidents occurred frequently in the past decade in China. This supported the opinion of Wachinger that social context could impact the public's perceptions (Wachinger et al. 2013).

The perception of flood risk includes four items in our study and details are shown in Table 3. The mean value and standard deviation of "Probability of floods perceived" are the highest. The mean value and standard deviation of "Social stability losses perceived" are the lowest. Table 3 indicates that the perceived probability of floods in study area is greater than the perceived losses either direct losses (e.g., economic losses and life losses) or indirect losses (e.g., social stability losses).

Although the respondents lived on a floodplain, most of them had no direct experience of floods (Table 4). Only $11.7 \%$ of our sample have experienced at least a flood. More respondents have experienced earthquakes, typhoons and snowstorms other than floods, at $13.2 \%, 16.8 \%$ and $16.9 \%$, respectively. Very few respondents in the study area experienced landslides - the percentage was only $2.8 \%$. 
Table 4 Descriptive analysis of experience

\begin{tabular}{llcc}
\hline Item & Variables & Frequency & Percentage \\
\hline 1 & Having experienced a flood & 82 & 11.7 \\
2 & Having experienced an earthquake & 93 & 13.2 \\
3 & Having experienced a landslide & 20 & 2.8 \\
4 & Having experienced a typhoon & 118 & 16.8 \\
5 & Having experienced a snowstorm & 119 & 16.9 \\
\hline
\end{tabular}

The characteristics of social trust are shown in Table 5. The mean value of item 1 ("family members") is the highest. The army obtained more trust than others except for family members. The mean value of item 2 ("friends") is the lowest. This is consistent with the social context in China. Firstly, trusting family members is one of the characteristics of acquaintance society in China. Secondly, the army plays a particularly important role in disaster relief and response in China, which is further propagated by social media.

According to Table 6, more than half of the respondents prepared food (59.7\%), water (58.6\%), and medicine (78.4), and $88.8 \%$ of respondents know the location of the nearest hospital, which corresponds to the risk perception of health in the study area as mentioned above. Radios were prepared by few respondents, only accounting for $37 \%$ of the total.

Table 5 Descriptive analysis of social trust. NGO: nongovernmental organization

\begin{tabular}{llllll}
\hline Item & Variable & Mean & SD & Min. & Max. \\
\hline 1 & Trust family members & 3.722 & 0.703 & 0 & 4 \\
2 & Trust friends & 2.352 & 0.752 & 0 & 4 \\
3 & Trust neighborhood & 2.910 & 0.766 & 0 & 4 \\
4 & Trust colleague & 2.811 & 0.798 & 0 & 4 \\
5 & Trust volunteer & 3.006 & 0.895 & 0 & 4 \\
6 & Trust media organizations & 2.527 & 0.928 & 0 & 4 \\
7 & Trust army & 3.343 & 0.911 & 0 & 4 \\
8 & Trust government & 2.895 & 0.944 & 0 & 4 \\
9 & Trust NGO (e.g., Red Cross & 2.822 & 0.944 & 0 & 4 \\
& Society of China) & & & & \\
\hline
\end{tabular}

Table 6 Descriptive analysis of preparedness behavior

\begin{tabular}{llll}
\hline Item & Variables & Frequency & Percentage \\
\hline 1 & Food & 419 & 59.7 \\
2 & Flashlight & 315 & 44.8 \\
3 & Water & 412 & 58.6 \\
4 & Medicine & 551 & 78.4 \\
5 & Radio & 261 & 37.1 \\
6 & First aid kit & 336 & 47.8 \\
7 & Know the location of the nearest hospital & 624 & 88.8 \\
8 & Know the location of the emergency shelter & 368 & 52.3 \\
9 & Having participated in drills or exercise & 305 & 43.4 \\
10 & Purchased flood insurance if available & 305 & 43.4 \\
11 & Familiar with flood prevention knowledge & 414 & 58.9 \\
\hline
\end{tabular}


The score of risk perception, experience, social trust, and preparedness behavior was all calculated and mapped in Fig. 4a, b, c, d to show the spatial pattern. Figure 4a illustrates that the highest score of risk perception is in Xuanwu District, and the score in Qinhuai is the lowest. The respondents of the districts lying along the Yangtze River (e.g., Qixia, Gulou, and Jianye) perceive less flood risk than those in Xuanwu, Jiangning and Yuhuatai. As shown in Fig. 4b, the respondents in Qixia experienced the lowest number of disasters compared to others, with a score of 0.17 . The respondents in Jianye experienced more dangerous events than others. Based on Fig. 4c, the spatial distribution changed again. The trust score of Jiangning is more than other districts, and the score of Qixia is the lowest. When focusing on the score of mitigation behaviors (Fig. 4d), the result shows that the

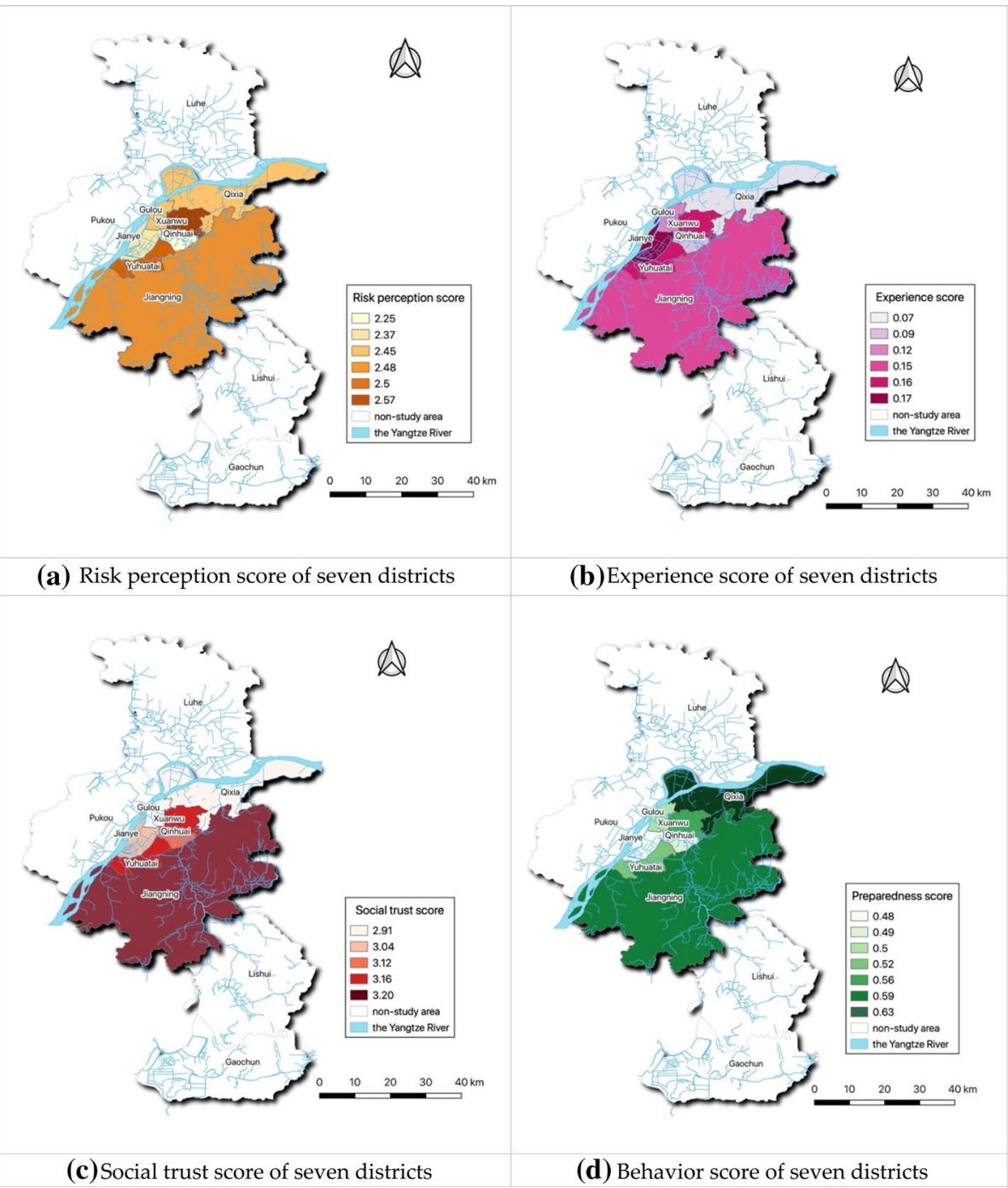

Fig. 4 The spatial pattern of risk perception, experience, social trust, and preparedness behavior 
respondents in Qixia prepared more than others, whereas, they perceive a not very high risk, experience the least hazards, and have the least social trust. And the respondents in Jianye prepared less than others. In conclusion, as for the scale of districts, non-significant relationship has been found between risk perception and experience, social trust, and preparedness behaviors.

\section{3 elationships regarding risk perception, exposure, experience, trust and behaviors}

First of all, the relationship between risk perception for floods and exposure is explored. In this paper, exposure is simplified as proximity to rivers (namely, the Euclidean distance to rivers). With the aid of QGIS 3.4.10, the distance from the centroid of each grid to the rivers is calculated and displayed in Fig. 5. And the descriptive statistics indicators of river proximity in each district were calculated by the Zonal statistics tool of QGIS 3.4.10 and shown in Table 7. Then, in order to further understand the relationship between risk perception and river proximity, we conducted Pearson's correlations that are defined as the covariance of the two variables divided by the product of their standard deviations (Gust and D'Journo 2015). The analyses revealed that the relationship was positive and statistically significant (Pearson's $r=0.766, p<0.05$ ). This result shows that the greater the distance between the respondent's residence (household) and the waterfront, the higher the perceived risk of a flood is.

Secondly, inferential testing was performed for the variables with chi-squared tests, for examining the relationships regarding risk perception, flood experience, social trust, and protective behaviors. As shown in Table 8, a relationship between flood experience and

Fig. 5 The spatial pattern of river proximity in Nanjing

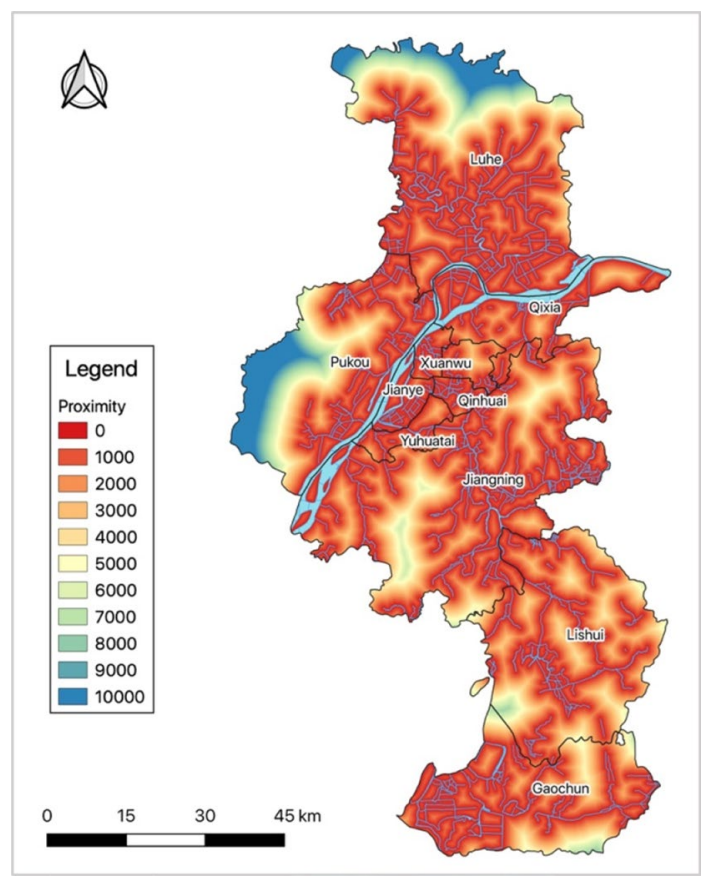


Table 7 Spatial analysis results of river proximity in study area

\begin{tabular}{lcrll}
\hline District & Mean $(\mathrm{m})$ & $\mathrm{SD}(\mathrm{m})$ & Min $(\mathrm{m})$ & $\operatorname{Max}(\mathrm{m})$ \\
\hline Jiangning & 1437.6 & 1029.6 & 0.0 & 6711.3 \\
Yuhuatai & 876.9 & 762.8 & 0.0 & 2926.1 \\
Jianye & 294.5 & 187.9 & 0.0 & 1922.6 \\
Qinhuai & 426.2 & 327.6 & 0.0 & 1985.6 \\
Xuanwu & 1334.6 & 1226.7 & 0.0 & 3849.7 \\
Gulou & 617.1 & 449.4 & 0.0 & 2230.6 \\
Qixia & 781.7 & 590.1 & 0.0 & 3443.7 \\
\hline
\end{tabular}

Table 8 Inferential results for risk perception, experience, social trust and protective behavior

\begin{tabular}{|c|c|c|c|c|c|}
\hline \multicolumn{6}{|c|}{ Relationship with risk perception of flood } \\
\hline Domain & Variables & Probability & Economic loss & Life loss & Social stability loss \\
\hline Experience & Flood experience & $0.165 * *$ & $0.125^{*}$ & $0.152 * *$ & $0.132 *$ \\
\hline \multirow[t]{9}{*}{ Trust } & Family member & $0.118^{* *}$ & $0.102^{*}$ & I & $0.123 * * *$ \\
\hline & Friend & $0.141^{* * *}$ & $0.101^{*}$ & I & $0.120 * * *$ \\
\hline & Neighborhood & $0.160 * * *$ & $0.100^{*}$ & l & $0.118^{* * *}$ \\
\hline & Colleague & $0.150^{* * *}$ & $0.102^{*}$ & $0.109^{* *}$ & $0.119 * * *$ \\
\hline & Volunteer & $0.132 * * *$ & $0.132 * * *$ & $0.120 * * *$ & $0.151 * * *$ \\
\hline & Media organization & $0.138 * * *$ & $0.141 * * *$ & $0.127 * * *$ & $0.133 * * *$ \\
\hline & Army & $0.123 * *$ & $0.103 *$ & l & $0.135 * * *$ \\
\hline & Government & $0.148^{* * *}$ & $0.137 * * *$ & $0.115^{* *}$ & $0.150 * * *$ \\
\hline & NGO & $0.137 * * *$ & $0.111 * *$ & l & $0.162 * * *$ \\
\hline \multirow[t]{11}{*}{ Behavior } & Prepare food & l & l & l & l \\
\hline & Prepare flashlight & $0.147 * *$ & l & l & l \\
\hline & Prepare water & l & l & l & l \\
\hline & Prepare medicine & l & l & l & l \\
\hline & Prepare radio & $0.243 * * *$ & l & $0.162 * * *$ & $0.168 * * *$ \\
\hline & Prepare first aid kit & l & l & l & l \\
\hline & $\begin{array}{l}\text { Know the location of nearest } \\
\text { hospital }\end{array}$ & I & I & I & I \\
\hline & $\begin{array}{l}\text { Know the location of emer- } \\
\text { gency shelter }\end{array}$ & l & l & $0.121^{*}$ & l \\
\hline & Participated in drills/exercise & $0.199 * * *$ & $0.124 *$ & $0.137^{*}$ & $0.134^{*}$ \\
\hline & Purchasing flood insurance & $0.143 *$ & $0.144 * *$ & $0.179 * * *$ & l \\
\hline & Familiar with flood knowledge & $0.137 *$ & I & I & $0.119^{*}$ \\
\hline
\end{tabular}

Results significant at the $* p<0.05, * * p<0.01, * * * p<0.001$ levels

four variables of risk perception had been found (with Cramer's V values of 0.165, 0.125, 0.152 and 0.132 ). This positive relationship is consistent with the findings of other studies (Miceli et al. 2008; Paton et al. 2008; Ruinet al. 2007). All the variables in the domain of trust link to respondents' perceptions. The findings suggest that trust is a significant predicator of perceived flood risk, which supports findings from the literature. However, the strength of correlations varied among different items of risk perception and trust variables. 
Trusting volunteers, the government and NGOs shows a stronger relationship to the social stability loss perceived by respondents (their Cramer's V values are all higher than 0.135 ). This is because they are closely related to rescue and social stability after disasters in China. Trusting friends, the neighborhood, and colleagues is linked more to the "probability" perceived by respondents. A possible explanation is that, living in an acquaintance society, respondents are used to relying on friends, the neighborhood, and colleagues to resist floods on a small scale. The effect of trust on "economic loss" is weaker except for the variable of "media organization" (with a Cramer's V of $0.141, p<0.001$ ), which is partly because more than $98 \%$ of the residents in our study area obtain the economic loss information of floods through media organizations. In addition, no relationship was found between "life loss" and five trust variables.

As for the domain of protective behavior, the item of "probability" in the risk perception domain had the strongest relationship with protective measures. As illustrated in Table 8, "probability" correlates with "prepare flashlight," "prepare radio," "participated in drills or exercise," "purchasing flood insurance" and "familiar with flood knowledge." The effect of "economic loss" on protective measures is the smallest. "Economic loss" is only related to "participated in drills or exercise" (with a Cramer's V of $0.124, p<0.05$ ) and "purchasing flood insurance" (with a Cramer's V of $0.144, p<0.01$ ). For respondents who are aware of flood risk, the most popular protective behavior is "participated in drills or exercise." "Preparing radio" and "purchasing flood insurance" are also popular measures that residents who perceive flood risk are willing to take. Our results also show that no relationship can be found between all four items of risk perception and some protective behaviors such as "food," "water," "medicine," "first aid kit" and "know the location of nearest hospital."

\section{Discussion}

The present study has contributed to exploring the relationship between risk perception and flood experience, social trust, and protective behaviors, and also to making a spatial picture of these four parts. With a survey performed in Nanjing, China, we firstly demonstrated descriptive analyses of four different themes, such as risk perception, experience, social trust and preparedness behavior. Results shows that most of the respondents living on a floodplain have no direct experience of floods. In our study area, the risk of flood is neglected, while the risk of pollution and health were perceived by the majority of respondents. This result has also been demonstrated by other studies (Ban et al. 2017; Li and Hu 2018; Liao et al. 2015; L. Wang and Watanabe 2019).

Secondly, with sample data, the score of risk perception, experience, social trust, and preparedness behavior was calculated and assembled on the scale of districts. Then, their spatial pattern was displayed and analyzed with QGIS 3.4.10. The spatial distributions of risk perception, experience, social trust and protective behaviors remain inconsistent: the highest score of risk perception is in Xuanwu District, the respondents in Jianye experienced more dangerous events than others, the trust score of Jiangning is more than other districts, and the respondents in Qixia prepared most. In conclusion, as for the scale of districts, no significant spatial relationship has been found among risk perception and experience, social trust, and preparedness behaviors.

Therefore, quantitative methods were conducted to further examine the relationships among these variables. With the aid of the Zonal statistics tool in QGIS 3.4.10, a spatial analysis and Pearson's correlations were conducted to explore the relationship between risk 
perception and river proximity. The finding revealed that river proximity has a significant effect on risk perception. Namely, spatial heterogeneity exists even in the same floodplain. Several researchers also observed a significant relation between risk perceptions and proximity to the hazard, while the existing evidence relating risk perception to proximity to the hazard is mixed, either positive or negative (Lechowska 2018; Wouter Botzen 2013). In our study area, the residents near rivers perceive less flood risk than the others. As shown in Fig. 5, the river proximity means the distance of every objects to the nearest river in our study. As a floodplain, there are so many small tributaries of the Yangtze River in our study area, however, they haven't caused devastating damage to the residents near rivers. And most small or medium floods can be effectively avoided by levees, then the number of damaging floods in this range is indeed decreasing as a result (Tadeusz and Piotr 2017). However, structural mitigation through construction of protective infrastructure and resistant structures (e.g., levee) will produce the illusion of safety. White (1945) theorizes that flood mitigation structures might increase flood risk, as protection from frequent flooding reduces the public risk awareness, which is called as "the levee effect" (Ridolfi et al. 2020). Hence, it can be inferred that levees in study area have led these residents to having a "low" risk perception of flooding even ignoring the risk of the Yangtze River. Whereas, the residences live far away rivers, they are still aware of flood risks caused by the Yangtze River because they don't have this illusion of safety and certainty. Therefore, more attention should be paid and more non-structural measures should be taken to the areas near rivers for reducing risk. For example, smart urban planning can be applied to enhance flood preparation (e.g., via spatial requirements for evacuation). Additionally, compensation and insurance schemes may be carried out as incentives or disincentives to enhance residents' resilience (Kundzewicz et al. 2018).

Last but not least, inferential testing was performed for the variables with chi-squared tests, for examining the relationships regarding risk perception, flood experience, social trust, and protective behaviors. (1) Flood experience was related to risk perception statistically significant. This positive relationship is consistent with the findings of other studies (Miceli et al. 2008; Paton et al. 2008; Ruin et al. 2007). Thus, there is need for more perception and awareness creation on the damages of flood risk among the residents in the study area (Onwuemele 2018). Burningham et al. highlight the importance of engaging with local perspectives on risk and making residents be a part of 'awareness-raising' processes (Burningham et al. 2008). Also, a more sophisticated flood-warning system can help people who are exposed to flood risk but are unaware (O'Neill et al. 2016). (2) Social trust has a significant relationship to perceived flood risk, other studies in risk literature support the findings in this study (Flynn et al. 1992; Ross et al. 2014; Ryu et al. 2018). We also found that the strength of the correlations varied among different items of risk perception and trust variables as mentioned above. It can be inferred that this result is affected by the mode of rescue in China and the characteristics of social and demographic features in China. The studies of other researchers also proved that social and demographic features play a major role in shaping the public perception of natural disasters (Armas and Avram 2009; Chauvin et al. 2007; Zaalberg et al. 2009). It also indicated that the public image of government, NGO, volunteers, and media organization have important effect on social trust on the dimension of flood loss perceived. The researches of Weerd et al. (Van Der Weerd et al. 2011)and Park (Park and Sohn 2013) also identified that public risk perception are associated with government trust, media communication. (3) The inferential results proved that flood risk perceived by respondents can affect several protective behaviors. This is consistent with the findings in the literature of risk perception and management (Nguyen 2013; Wang et al. 2018). As mentioned above, residents aware of flood risk are 
willing to take such measures as "participated in drill or exercise," "preparing radio" and "purchasing flood insurance." This finding shows an opportunity for local government to implement a regular emergency drill and establish flood insurance program. Additionally, we can infer that local respondents have recognized the importance of communication of disaster information according to the measure of "preparing radio." Hence, it's necessary for local government to establish a reliable and integrated information dissemination mechanism to improve public emergency response and preparedness during disasters as suggested by other researcher (Zhang et al. 2014). Our results also show that no relationship can be found between all four items of risk perception and some protective behaviors such as "food," "water," "medicine," "first aid kit" and "know the location of nearest hospital." Except preparing "first aid kit," the other four items are actually prepared by most residents no matter whether flood even disasters happen.

This study had three limitations. First, because of the high frequency of environmental and health incidents in China, the risk perception of natural disasters is so low that it may affect the context of our survey. Second, only the direct experience of floods is focused and the indirect experience of floods isn't included in our study. Third, according to the Chinese government's efforts against the snow disaster in southern China in 2008 and the Wenchuan Earthquake in 2008, and the Chinese government responds to the COVID-19 pandemic in 2020, it can be concluded that the risk government in China is the mode of "nationwide catastrophe response" mode (namely the top down mode), which is different from "bottom up" risk governance mode widely adopted in the Western countries and some Asian countries (Shi et al. 2013). Hence, such a particular mode make Chinese people perceive risk in a different way from people in other countries. On the one hand, it proves that our research is important and valuable. On the other hand, it indicates that we should explore and analyze the differences of public risk perception influenced by risk governance mode between China and other countries in future research, especially during and after the COVID-19 pandemic.

\section{Conclusions}

This paper provided insight on the public perception of flood hazard and flood risk in a city prone to floods. With a case study, the public risk perception was examined and the links to exposure were tracked by spatial analysis. Meanwhile, inferential testing with chisquared tests was undertaken regarding experience, social trust, and protective behaviors. The findings of this study will help government to develop effective flood risk communication strategies for improving public awareness creation, emergency response and preparedness. Future work will focus on how the public risk perceptions change over the COVID-19 pandemic in China. Additional work will focus on exploring the differences of public risk perception and response behavior between two different governance modes: the Chinese "top down" mode (nationwide catastrophe response mode) and the "bottom up" mode.

Acknowledgements Special thanks to the reviewers and editors for their critical comments that greatly helped in improving the quality of this paper.

Author contributions Data curation, Yi Ge, Xueer Lu, Jie Mao; Formal analysis, Yi Ge and Xiaotao Wang; Methodology, Wen Dou; Resources, Guangfei Yang; Software, Wen Dou; Visualization, Wen Dou; Writing-original draft, Yi Ge. 
Funding This research was funded by the National Natural Science Foundation of China (Grant Nos. 41571488, 41401382, 41571342 and 41701186), the Philosophy and Social Sciences Foundation in Jiangsu Province (Grant No. 17JDB010), and the Ministry of Education Humanities and Social Science Fund (Grant No.17YJCZH029).

\section{Compliance with ethical standards}

Conflicts of interest The authors declare no conflict of interest.

\section{References}

Arias JP, Bronfman NC, Cisternas PC, Repetto PB (2017) Hazard proximity and risk perception of tsunamis in coastal cities: are people able to identify their risk? PLoS ONE 12(10):1-13

Armas I, Avram E (2009) Perception of flood risk in Danube delta, Romania. Nat Hazards 50:269-287

Avram ÆE (2009) Perception of flood risk in Danube Delta, Romania. Nat Hazards 50(2):269-287

Ban J et al (2017) The health policy implications of individual adaptive behavior responses to smog pollution in urban China. Environ Int 106:144-152. https://doi.org/10.1016/j.envint.2017.06.010

Biel A, Dahlstrand U (1995) Risk perception and the location of a repository for spent nuclear fuel. Scand J Psychol 36:25-36

Bradford RA et al (2012) Risk perception-issues for flood management in Europe. Nat Hazards Earth Syst Sci 12:2299-2309

Brilly M, Polic M (2005) Public perception of flood risks, flood forecasting and mitigation. Nat Hazards Earth Syst Sci 5(3):345-355

Bronfman NC, E Lo'pez-Va'zquez, VV Gutie'rrez, and LA Cifuentes. (2008) Trust, acceptance and knowledge of technological and environmental hazards in Chile. J Risk Res 11(6):755-773

Bubeck P, Botzen WJW, Aerts JCJH (2012) A review of risk perceptions and other factors that influence flood mitigation behavior perceptions and private. Risk Anal Int J 32(9):1481-1495

Bui DT, Panahi M, Shahabi H, Singh VP (2018) Novel hybrid evolutionary algorithms for spatial prediction of floods. Sci Rep 8:15364. https://doi.org/10.1038/s41598-018-33755-7

Burningham K, Fielding J, Thrush D (2008) 'It'll never happen to me': understanding public awareness of local flood risk. Disasters 32(2):216-238

Cardwell FS, Elliott SJ (2019) Understanding an environmental health risk: investigating asthma risk perception in Ontario youth sport. Int J Environ Res Public Health 16(11):2033

Chauvin B, Hermand D, Mullet E (2007) Risk perception and personality facets. Risk Anal 27:171-185

Choon S-W, Ong H-B, Tan S-H (2019) Does risk perception limit the climate change mitigation behaviors? Environ Dev Sustain 21(4):1891-1917. https://doi.org/10.1007/s10668-018-0108-0

Cui Ke, Han Z (2018) Resilience of an earthquake-stricken rural community in southwest China: correlation with disaster risk reduction efforts. Int J Environ Res Public Health 2030(March):407

Der Weerd V, Willemien, et al (2011) Monitoring the level of government trust, risk perception and intention of the general public to adopt protective measures during the influenza A (H1N1) pandemic in the Netherlands. BMC Public Health 11:575

Felgentreff C (2003) Post-disaster situations as 'windows of opportunity'? post-flood perceptions and changes in the german odra river region after the 1997 flood. Erde 134(2):163-180

Flynn J, Burns W, Mertz CK, Slovic P (1992) Trust as a determinant of opposition to a high-level radioactive waste repository: analysis of a structural model. Risk Anal 12:417-429

Ge Yi, Dou W, Zhang H (2017) A new framework for understanding urban social vulnerability from a network perspective. Sustainablity 9:1-16

Gust L, D'Journo XB (2015) The use of correlation functions in thoracic surgery research. J Thorac Dis 7(3):E11-E15

Hall TE, Slothower M (2009) Cognitive factors affecting homeowners' reactions to defensible space in the oregon coast range. Soc Nat Resour 22:95-110

Heitz C, Spaeter S, Auzet AV, Glatron S (2009) Local stakeholders' perception of muddy flood risk and implications for management approaches: a case study in Alsace (France). Land Use Policy 26(2):443-451

Hulin C, Netemeyer R, Cudeck R (2001) Can a reliability coefficient be too high? J Consum Psychol 10(1):55-58 
Hung HV, Shaw R, Kobayashi M (2007) Flood risk management for the RUA of Hanoi: importance of community perception of catastrophic flood risk in disaster risk planning. Disaster Prev Manag Int J 16(2):245-258

Jiang T, Zhang Q, Blender R, Fraedrich K (2005) Yangtze delta floods and droughts of the last millennium: abrupt changes and long term memory. Theoret Appl Climatol 82(3-4):131-141

Joshi A, Saket K, Chandel S, Pal DK (2015) Likert scale: explored and explained. Br J Appl Sci Technol 7(4):396-403

Kaźmierczak A, Cavan G (2011) Surface water flooding risk to urban communities: analysis of vulnerability, hazard and exposure. Landsc Urban Plan 103(2):185-197

Kellens W et al (2011) An analysis of the public perception of flood risk on the Belgian coast. Risk Anal 31(7):1055-1068

Khosravi K et al (2019) A comparative assessment of flood susceptibility modeling using multi-criteria decision-making analysis and machine learning methods. J Hydrol 573:311-323

Krasovskaia I, Gottschalk L, Sælthun NR, Berg H (2001) Perception of the risk of flooding: the case of the 1995 flood in Norway. Hydrol Sci J 46(6):855-868

Kundzewicz ZW, Hegger DLT, Matczak P, Driessen PPJ (2018) Flood-risk reduction: structural measures and diverse strategies. Proc Natl Acad Sci USA 115(49):12321-12325

Lechowska E (2018) What determines flood risk perception? a review of factors of flood risk perception and relations between its basic elements. Nat Hazards 94(3):1341-1366. https://doi.org/10.1007/s1106 9-018-3480-z

Li Z, Bin Hu (2018) Perceived health risk, environmental knowledge, and contingent valuation for improving air quality: new evidence from the Jinchuan mining area in China. Econ Hum Biol 31:54-68. https ://doi.org/10.1016/j.ehb.2018.07.007

Liang W et al (2011) Flood disaster in Taihu Basin, China: causal chain and policy option analyses. Environ Earth Sci 63(5):1119-1124

Liao X et al (2015) Residents' perception of air quality, pollution sources, and air pollution control in Nanchang, China. Atmos Pollut Res 6:835-841

Lindell MK, Hwang SN (2008a) Household's perceived personal risk and responses in a multihazard environment. Risk Anal 28:539-556

Lindell MK, Hwang SN (2008b) Households' perceived personal risk and responses in a multihazard environment. Risk Anal 28(2):539-556

Lindell MK, Perry RW (2000) Household adjustment to earthquake hazard: a review of research. Environ Behav 32:461-501

Ludy J, Kondolf GM (2012) Flood risk perception in lands 'protected' by 100-year levees. Nat Hazards 61(2):829-842

Miceli R, Sotgiu I, Settanni M (2008) Disaster preparedness and perception of flood risk: a study in an alpine valley in Italy. J Environ Psychol 28:164-173

Ming-Chou Ho, Shaw D, Shuyeu L, Yao-Chu C (2008) How do disaster characteristics influence risk perception? Risk Anal 28(3):635-643

NASA (2016) Flooding in China. https://earthobservatory.nasa.gov/images/88467/flooding-in-china. Accessed from 6 Oct 2019

Nguyen M (2013) Living with floods: protective behaviours and risk perception of Vietnamese households. Gen Pap Risk Insur Issues Pract 2005:547-579

O'Neill E, Brereton F, Shahumyan H, Peter Clinch J (2016) The impact of perceived flood exposure on flood-risk perception: the role of distance. Risk Anal 36(11):2158-2186

Onwuemele A (2018) Public perception of flood risks and disaster preparedness in lagos megacity, Nigeria. Acad J Interdiscip Stud 7(3):179-185

Pagneux E, Gísladóttir G, Jónsdóttir S (2011) Public perception of flood hazard and flood risk in iceland: a case study in a watershed prone to ice-jam floods. Nat Hazards 58(1):269-287

Park J-E, Sohn A (2013) The influence of media communication on risk perception and behavior related to mad cow disease in south Korea. Osong Public Health Research Perspect 4(4):203-208

Paton D, Smith L, Daly M, Johnston D (2008) Risk perception and volcanic hazard mitigation: individual and social perspectives. J Volcanol Geoth Res 172(4):179-188

Qin DH, Zhang JY, Shan CC, Song LC (2015) China national assessment report on risk management and adaptation of climate extremes and disasters. Science Press, Beijing

Ridolfi E, Albrecht F, Di Baldassarre G (2020) Exploring the role of risk perception in influencing flood losses over time. Hydrol Sci J 65(1):12-20. https://doi.org/10.1080/02626667.2019.1677907

Ross VL, Fielding KS, Louis WR (2014) Social trust, risk perceptions and public acceptance of recycled water: testing a social-psychological model. J Environ Manage 137:61-68. https://doi.org/10.1016/j. jenvman.2014.01.039 
Ruin I, Gaillard JC, Lutoff C (2007) How to get there? assessing motorists' flash flood risk perception on daily itineraries. Environ Hazards 7(3):235-244

Ryu Y, Kim S, Kim S (2018) Does trust matter? analyzing the impact of trust on the perceived risk and acceptance of nuclear power energy. Sustainability 10(3):758 ((Switzerland))

Scolobig A, De Marchi B, Borga M (2012) The missing link between flood risk awareness and preparedness: findings from case studies in an alpine region. Nat Hazards 63:499-520

She $\mathrm{S}$ et al (2019) An exploration of hiking risk perception: dimensions and antecedent factors. Int J Environ Res Public Health 16(11):1986

Shi P, Ye Q, Jaeger C (2013) Intergrated risk governance: science plan and case studies of large-scale. In: Ye Q, Jaeger C (eds) Peijun Shi. Springer, Berlin Heidelberg

Shin M et al (2019) Public perceptions of environmental public health risks in the United States. Int J Environ Res Public Health 16(6):1-13

Siegrist M (2000) The influence of trust and perceptions of risks and benefits on the acceptance of gene technology. Risk Anal 20:195-203

Siegrist M, Cvetkovich G (2000) Perception of hazards: the role of social trust and knowledge. Risk Anal 20:713-720

Siegrist M, Gutscher H (2006) Flooding risks: a comparison of lay people' s perceptions and expert' s assessments in Switzerland. Risk Anal 26(4):971-979

$\mathrm{Sj}$ "oberg, L. (2002) Attitudes to technology and risk: going beyond what is immediately given. Policy Sci 35:379-400

Sjöberg L (2001) Limits of knowledge and the limited importance of trust. Risk Anal 21(1):189-198

Su W, Duan H (2017) Catchment-based imperviousness metrics impacts on floods in Niushou river basin, Nanjing City, east China. Chin Geogra Sci 27(2):229-238

Tadeusz T, Piotr Z (2017) Large risks with low probabilities: perceptions and willingness to take preventive measures against flooding. In: Piotr Z (ed) Tyszka Tadeusz. IWA, London

Tavakol M, Dennick R (2011) Making sense of Cronbach's alpha. Int J Med Educ 2:53-55

Terpstra T (2011) Emotions, trust, and perceived risk: affective and cognitive routes to flood preparedness behavior. Risk Anal 31(10):1658-1675

Thieken AH, Kreibich H, Müller M, Merz B (2007) Coping with floods: preparedness, response and recovery of flood-affected residents in Germany in 2002. Hydrol Sci J 52(5):1016-1037

Thistlethwaite J, Henstra D, Brown C, Scott D (2018) How flood experience and risk perception in FI Uences protective actions and behaviours among Canadian homeowners. Environ Manage. https:// doi.org/10.1007/s00267-017-0969-2

Tien Bui D et al (2019) Flood spatial modeling in northern Iran using remote sensing and GIS: a comparison between evidential belief functions and its ensemble with a multivariate logistic regression model. Remote Sens 11:1589

Viklund MJ (2003) Trust and risk perception in Western Europe: a cross-national study. Risk Anal 23(4):727-738

Wachinger G, Renn O, Begg C, Kuhlicke C (2013) The risk perception paradox-implications for governance and communication of natural hazards. Risk Anal 33(6):1049-1065

Wang L, Watanabe T (2019) Effects of environmental policy on public risk perceptions of haze in Tianjin city: a difference-in-differences analysis. Renew Sustain Energy Rev 109(March):199-212. https ://doi.org/10.1016/j.rser.2019.04.017

Wang Yi et al (2019) Flood susceptibility mapping in Dingnan county (China) using adaptive neurofuzzy inference system with biogeography based optimization and imperialistic competitive algorithm. J Environ Manage 247:712-729

Wang Z et al (2018) Analysis of the public flood risk perception in a flood-prone city: the case of Jingdezhen city in China. Water (Switzerland) 10(11):1577

Wikipedia (2012) 2011 China floods. https://en.wikipedia.org/wiki/2011_China_floods\#cite_note-china losses-5. Accessed from 6 Oct 2019

Wouter Botzen WJ (2013) Managing extreme climate change risks through insurance. Cambridge University Press, United Kingdom

Wu G, Han Z, Weijin Xu, Gong Y (2018) Mapping individuals' earthquake preparedness in China. Nat Hazards Earth Syst Sci 18(5):1315-1325

Xie Z, Yin Du, Zeng Y, Miao Q (2018) Classification of yearly extreme precipitation events and associated flood risk in the Yangtze-Huaihe river valley. Sci China Earth Sci 61(9):1341-1356

Yong AG, Lemyre L (2019) Getting Canadians prepared for natural disasters: a multi-method analysis of risk perception, behaviors, and the social environment. Nat Hazards 98(1):319-341. https://doi. org/10.1007/s11069-019-03669-2 
Zaalberg R, Midden C, Meijnders A, McCalley T (2009) Prevention, adaptation, and threat denial: flooding experiences in the Netherlands. Risk Anal 29:1759-1778

Zhang $\mathrm{N}$ et al (2014) Information dissemination analysis of different media towards the application for disaster pre-warning. PLoS ONE 9(5):e98649

Zhang Y, Hwang SN, Lindell MK (2010) Hazard proximity or risk perception? evaluating effects of natural and technological hazards on housing values. Environ Behav 42(5):597-624

Publisher's Note Springer Nature remains neutral with regard to jurisdictional claims in published maps and institutional affiliations. 